Revista de la red interuniversitaria de estudios sobre las literaturas rioplatenses contemporáneas en Francia

\title{
Máscaras y simulacros : nuevas políticas del sujeto y la narración
}

\author{
Ana María Amar Sánchez
}

\section{OpenEdition \\ Journals}

Edición electrónica

URL: http://journals.openedition.org/lirico/1144

DOI: $10.4000 /$ lirico. 1144

ISSN: 2262-8339

Editor

Réseau interuniversitaire d'étude des littératures contemporaines du Río de la Plata

\section{Referencia electrónica}

Ana María Amar Sánchez, "Máscaras y simulacros : nuevas políticas del sujeto y la narración », Cuadernos LIRICO [En línea], 9 | 2013, Puesto en línea el 01 septiembre 2013, consultado el 03 mayo 2019. URL : http://journals.openedition.org/lirico/1144; DOI : 10.4000/lirico.1144

Este documento fue generado automáticamente el 3 mayo 2019.

\section{cc) $(1) \odot$}

Cuadernos LIRICO está distribuido bajo una Licencia Creative Commons Atribución-NoComercialSinDerivar 4.0 Internacional. 


\title{
Máscaras y simulacros : nuevas políticas del sujeto y la narración
}

\author{
Ana María Amar Sánchez
}

1 Las relaciones entre estética y política han sido objeto de interés para la crítica literaria desde siempre y, a lo largo del siglo XX, han producido numerosas reflexiones teóricas. En los comienzos del nuevo siglo asistimos a una reconsideración de este vínculo que supone también enfocar la atención en formas narrativas que han venido a señalar cambios en la literatura actual y en el nexo que establecen, justamente, entre lo estético y lo político. Si, como afirma Rancière, "no hay ningún conflicto entre la pureza del arte y su politización » puesto que « un arte crítico es un arte que sabe que su efecto político pasa por la distancia estética $»^{1}$, es posible percibir un territorio común a la literatura y a la política que sería el territorio de la estética : el arte, la literatura, ensayan entonces, ya sea en sus formas más explícitas o más elusivas, una particular configuración de estas relaciones. La cuestión será cómo diseñan esas configuraciones, qué tipo de soluciones encuentran al intento de fusionar lo político con una forma estética específica.

2 Una de las estrategias narrativas objeto de la particular atención de la crítica en los últimos años ha sido la llamada " autoficción ». ${ }^{2}$ Esta atracción se explica en parte por los numerosos textos literarios en que puede observarse este procedimiento y el debate que provoca su presencia en las obras de algunos de los autores más significativos del presente. Sin duda puede rastrearse el uso de formas « autoficcionales» en textos muy anteriores, pero este « retorno » implica nuevos enfoques teóricos y nuevas lecturas de su función y sentido. Mi hipótesis en este trabajo piensa esta figura como un espacio donde se da una de esas « particulares configuraciones » que anudan el lazo, en su articulación entre lo textual y lo referencial, entre política y estética.

Los textos autoficcionales tienen en común su naturaleza contradictoria (y en ello reside gran parte de su atracción), pues suelen leerse como híbridos que tienden a borrar las diferencias entre los géneros y plantear una imaginaria identificación entre el autor real y su representación textual. José Amícola propone una de las definiciones más interesantes sobre la autoficción moderna al concebirla como « un mecanismo especular 
por el que se produce un reflejo (sesgado) del autor o del libro dentro del libro » (72); esto le recuerda «la técnica pictórica del Renacimiento y el Barroco llamada in figura, por la que el pintor aparecía en el lienzo ocupando un margen del cuadro pero travestido en un personaje afin al tema pintado » (72). El nombre del autor que firma el libro e ingresa en el texto -o un personaje narrador que aparece como su alter ego- origina este efecto.

4 Ya Foucault en « ¿Qué es un autor?» - trabajo que lejos de plantear la muerte del autor antes bien lleva el problema al centro de la discusión- señalaba que « sería falso buscar al autor tanto del lado del escritor real como del lado de ese locutor ficticio ; la funciónautor se efectúa en la escisión misma, en esa decisión y en esa distancia » (98). ${ }^{3}$ Del mismo modo, Derrida en "Políticas del nombre propio" se propone debilitar la fuerza que otorgamos a un nombre, ya sea en una autobiografía, en un texto histórico o de ficción, y denomina « efecto de ingenuidad » el producido en nosotros por la fuerza persuasiva del lenguaje que nos hace creer que una firma «corresponde, de manera natural y obvia, al cuerpo de un hombre singular » (292). La autoficción juega con esos márgenes borrosos entre lo real y lo textual; y esto ha dado lugar a lecturas muy diversas, ellas mismas oscilando en sus perspectivas entre lo autobiográfico y lo ficcional. ${ }^{4}$

5 Sin duda el estudio de Alberca ha contribuido ampliamente a la discusión y algunos de sus planteos han sido objeto de polémica: sostiene que las autoficciones son novelas de imaginación, pero al atribuir a su protagonista la misma identidad del autor, parecen comprometerse a ser verídicas como las autobiografías. ${ }^{5}$ Morales-Rivera cuestiona la lectura que hace Alberca de obras "equívocamente autobiográficas » : al insistir en la preminencia de lo autorial sobre lo ficticio se produce un efecto que contradice la ambigüedad sobre la que se basa el simulacro autobiográfico; se diluiría así el aspecto crítico de ese tipo de obras que es, precisamente, « cuestionar la figura autorial, es decir, revelar la ambigüedad que caracteriza a toda autoría y autoridad» (142). En este sentido, el término de «simulacro autobiográfico » (142) -acuñado por Morales-Rivera para referirse al cuestionamiento de los límites entre personaje y autor y entre ficción y realidad en La soledad era esto de Juan José Millás- es particularmente útil en la medida en que no permite dejarse atrapar por lo biográfico y referencial, a la vez que lleva a primer plano la condición literaria, el aspecto constructivo de este procedimiento narrativo.

6 En el mismo sentido, Premat retoma la función-autor de Foucault y propone « agregarle una ficción de autor (si se quiere, la ficción de autor sería, al igual que el nombre, parte integrante de esa función)» (13); la inestabilidad de esa «identidad que escribe » se organiza en esa ficción, que no fija rasgos sino que acompaña la ambigüedad del texto. Se podría hablar -según Premat- de una «ilusión biográfica», así como hay una «ilusión referencial» (24); es decir, el autor es « una figura inventada por la sociedad y por el sujeto, tanto como es un efecto textual » (26). ${ }^{6}$

7 En resumen, los datos que el lector posee de los autores funcionan como un guiño, generan un sujeto "bisagra " oscilando entre «lo exterior y lo interior» del texto, producen un efecto que, ya sea lo llamemos « autoficción », « simulacro autobiográfico » o "ficción de autor», establece un gesto cómplice muy claro al que Alberca también denomina un pacto ambiguo. Esta estrategia sin duda desestabiliza y cuestiona las perspectivas convencionales sobre las nociones de narrador y autor, y nos lleva a pensar en estas categorías de una manera diferente. ${ }^{7}$

8 Me enfocaré en dos tipos de relatos que proponen formas de vincularse con lo político muy distintas : en primer lugar, textos literarios que no se plantean abiertamente como una narrativa política -al menos de un modo tradicional-; por el contrario, en ellos 
parecen primar las preocupaciones estéticas y, sin embargo, sus modos de representación proponen una lectura y un rechazo de los resultados de las transformaciones históricosociales del siglo XX. Es decir, me pregunto cómo leer lo político y una evaluación de la historia en una narrativa que no habla de los hechos, pero que nos permite pensar en ellos y en sus consecuencias. Voy a ocuparme de la obra del uruguayo Mario Levrero - $\mathrm{La}$ novela luminosa (2005)- y del puertorriqueño Eduardo Lalo - Países invisibles (2008)- ${ }^{8}$; ambos autores aparentemente distantes entre sí y pertenecientes a mundos culturales, geográficos y políticos muy diferentes. ${ }^{9}$ Estos relatos dan cuenta de esos procesos de modos diversos y «sesgados", producen desplazamientos y rupturas con los sistemas canónicos de representación de lo político, plantean un desapego y una desilusión que hace a los personajes casi «invisibles» en un mundo en el que indudablemente no se sienten cómodos. En segundo lugar, me referiré a El hombre que amaba los perros (2009) de Leonardo Padura, novela en la que difícilmente puede soslayarse la presencia de lo político como rasgo dominante y cuyo protagonista comparte un similar desencanto con los anteriores.

9 Sorprende encontrar procedimientos comunes en estas manifestaciones surgidas en ámbitos culturales y con proyectos estéticos tan diversos. Sin embargo, sabemos que muchos textos pertenecientes a la literatura latinoamericana han dialogado desde siempre y establecido múltiples redes entre sí, lo que permite analizar aquellos gestos comunes que delatan similares preocupaciones y problemáticas. En este caso, no sólo comparten la cercanía temporal, todos se han publicado en la primera década del nuevo siglo, sino que coinciden en ser un tanto «inclasificables" por su imprecisa condición genérica y, en especial, por un uso de la voz narrativa igualmente ambigua. A pesar de sus diferencias, los lectores pueden notar en todos los casos un uso y una mezcla muy libre y compleja de diversos géneros : La novela luminosa se propone como un proyecto de novela construido, en su mayor parte, como un diario, que tal vez puede ser también un ensayo ; lo mismo vale para Los países invisibles de Eduardo Lalo que puede leerse como un ensayo, un diario, quizá una ficción -de hecho el narrador se pregunta « ¿Hasta qué punto esto es una novela?» (150). El hombre que amaba los perros es una ficción, pero dos de sus tres secciones llevan al lector a olvidar esto y se leen como biografías o novelas históricas. ${ }^{10} \mathrm{La}$ articulación o fusión de formas hace borrosa la adcripción a un género preciso e impide encasillar los textos. Pero, fundamentalmente y en todos los casos, comparten de modo muy notorio otra estrategia narrativa : los narradores-protagonistas juegan con el mismo efecto de « confusión » o mezcla entre lo real y lo referencial.

10 Encontramos, más allá de las diferencias entre las estéticas a las que pertenecen los relatos, un sujeto narrador complejo, problemático, punto de cruce entre ficción y referencialidad -y ésta es mi hipótesis, como ya señalé-, punto de cruce entre política y estética, entre referencia y autorreferencia. La reiteración de esta figura que parece fusionar autor/narrador/personaje en mucha de la narrativa de los últimos años no implica, por supuesto, volver a la categoría « autor » tradicional, sino analizar el sentido y función de esta compleja y peculiar figura en la que Premat ve un espacio para « proponer soluciones dinámicas » donde se construye « una coherencia, una dialéctica identitaria del que escribe» (12). Sin negar esta postura, creo que en la narrativa reciente, ese espacio es un lugar esencial donde poner en escena, representar la tensión entre política y textualidad.

11 Este sujeto funciona como un ámbito privilegiado, como un signo que señala a la vez hacia la escritura y hacia la referencia. Por una parte, a través de esa enunciación el texto se 
plantea como escritura : por ejemplo, el narrador de Lalo insiste en el hacer que lo ocupa : "¿Qué género es uno sin fronteras? ¿No será ya, de entrada, una incursión en lo novelístico el hecho de que este texto aborde como objeto de estudio la invisibilidad?» (150) y en Levrero leemos « para el lector común, tal vez este diario podría pasar por una novela, con un protagonista y unas situaciones inventadas por mí » (353) y más adelante " la forma más adecuada de resolver la novela luminosa es la autobiográfica » (436). ${ }^{11}$ Asimismo, los textos están atravesados por los comentarios acerca de libros, libros comprados, leídos y/o no comprados y deseados; los libros se comentan, se admiran o rechazan : leer y escribir es el espacio -casi el único espacio- por donde estos sujetos narradores se desplazan con comodidad. Esa figura está entonces profundamente unida a la escritura, revierte sobre la especificidad textual, obliga a atender a la situación de enunciación. Es ésta otra coincidencia con la novela de Padura que parece construida por "capas de escritura » a la manera de un palimpsesto : se teje una trama que contiene la historia del narrador y los relatos sobre Mercader y Trotsky, que recibió a través de cartas, libros e informes orales. Es constante su debate interno y sus dudas acerca de la posibilidad de escribir el texto -la novela- que cierra su amigo Daniel luego de su muerte en el capítulo « Requiem » y que se completa con la nota final del autor. ${ }^{12}$

12 Al mismo tiempo, esa construcción autoral, esa autoficción sería la "vía de salida ", el vaso comunicante con el « afuera », donde se inscribe la política tanto en los textos en los que no se narran hechos puntuales, sucesos o acontecimientos históricos precisos y que, incluso, parecen eludirlos como en $\mathrm{El}$ hombre que amaba los perros donde la figura del narrador Iván es el espacio de encuentro entre ficción, biografía, historia y política.

\section{El repliegue del yo : una estética de lo nimio}

13 En las dos primeras novelas consideradas, esa figura bien definida por la noción de « simulacro autobiográfico » se manifiesta en la coincidencia de nombres entre narrador y autor, tanto en Levrero quien remite en su novela a la otra parte de su nombre real ( « le explico también que yo soy Jorge Varlotta», 147) como en Países invisibles donde el narrador advierte : «De ahí que el lector tenga, por lo que pueda valer, un fragmento de ese ser de papel y tinta que es Eduardo Lalo » (129).

14 A través de " esa voz que enuncia », se representa un mundo exterior al que rechazan por igual ambos relatos y en el que es fundamental la oposición planteada por Lalo entre « lo visible »vs. «lo invisible ». ${ }^{13}$ Esta polaridad vale también para Levrero; de hecho, la dedicatoria ("Al país invisible ») y el epígrafe (« Mi reino es el exilio») del primero podrían usarse en el segundo: el "poder de la no-participación, el poder de la invisibilidad» (139) al que se refiere Lalo podría ser el motor que mueve al autor del diario en la obra de Levrero. Asimismo, esta oposición vale tanto para los países (ambos autores y textos pertenecen a países igualmente invisibles para el primer mundo) como para los sujetos. Ser visible, ver, ser visto, no querer ver son los términos por los que transitan unos y otros; a su vez, ese ver, o no querer ver, de los narradores introduce la referencialidad y la evaluación del « mundo de afuera ». Se trata de un ámbito que los dos textos desaprueban, en el que los narradores se sienten extraños: la frase de Lalo « Me siento tan ajeno a lo que me rodea que me siento casi en casa» (60) nuevamente es también válida para Levrero. La representación de este espacio remite al problema de las relaciones -y las tensiones- entre estética y política, entre textualidad y referencialidad, al problema de cómo se articulan ambos campos, y así lo señala el narrador de La novela 
luminosa al describir una escultura : "es simple, blanca, pura, contundente y luminosa. Eso no se puede conseguir con la literatura (222) [...] no tengo forma de transmutar los hechos reales de modo tal que se hagan "literatura" » (435). ${ }^{14}$

Sin duda, los narradores comparten un mismo gesto: se escribe para conjurar la invisibilidad o volver invisible un mundo hostil. En ambos, la inmersión en los libros y en la escritura permite dar la espalda al insoportable ruido de la ciudad, a la estupidez de los transeúntes y de los shoppings, a la pesadilla y la banalidad en que se ha convertido la vida en los comienzos del siglo XXI. El fastidio y el repliegue del narrador de La novela luminosa-obsesionado por los programas de computación y por observar el largo proceso de descomposición del cadáver de una paloma en una terraza- se evidencia en su agarofobia y su temor a enfrentar la vida urbana. Lalo recuerda cómo ese mundo sólo puede ser inteligible a través del lenguaje y define ese trabajo como un « hacer literatura de viaje sobre la ciudad de la que no se ha salido [...] Por eso es por lo que esta ciudad pertenece a la escritura » (146).

Territorio sin duda adverso en el que no vale la pena detener la mirada en casi nada, en el que los ciudadanos, las cosas, los sonidos, son sólo manifestaciones agresivas de un mundo ajeno y casi incomprensible. Dice el narrador de La novela luminosa :

Estos paseos por algo muy parecido al infierno me producen una sensación de irrealidad [...] la Intendencia participa en esta producción de ruido estupidizante ; y me imagino lo que será el país dentro de algunos años [...] el reino de la guarangada y la patota y seguramente un nuevo terrorismo de Estado (337-338). ${ }^{15}$

Y a la vez, leemos en el texto de Lalo un eco de lo anterior : « En el camino quedo detenido entre carros que tienen sus radios a todo volumen, creando una especie de generalizada agresión » (162).

La manera en que se anudan estética y política es particularmente interesante en ambos relatos, en tanto el elusivo modo de representar a esta última se sostiene gracias a un trabajo de escritura centrado en la enunciación, en una voz cuya complejidad borra -y problematiza- los límites convencionales reconocidos por la crítica para esa categoría. En ese sentido, el sujeto narrador, ese autor ficticio, esa " ficción de autor », es una estrategia clave para el análisis del registro político. Más allá de ser sólo un puro juego ficcional o un alter ego del autor, plantea otras posibilidades de lectura en textos en los que parece sostenerse en un delicado y ambiguo equilibrio.

personaje-autor complejiza las relaciones con la referencia y las cuestiona ; se diría que propone un paso más allá en el debate que corrió a lo largo del siglo XX sobre la figura del autor. En ésta también cobra fuerza una forma de llevar adelante la significación política de un texto ; es decir, ese sujeto ejerce una doble atracción : insiste en recordar que es escritura y la su vez su mirada hacia el mundo exterior lo evalúa y lo define como hostil y degradado. Es el espacio donde -retomando a Rancière- la distancia estética se muestra como política. Esa figura del narrador-autor es una forma de representar lo político; se trata de una configuración que dice lo político a través de su forma estética.

En ese cruce se construye un espacio en el que se manifiesta el malestar hacia un afuera donde la vida social parece invivible, en el que se ha quebrado toda alternativa de experiencia colectiva, de solidaridad y de futuro. Justamente, el resultado de este quiebre provoca un repliegue -más que una ausencia- de la emoción frente a la imposibilidad de una experiencia social directa; se produce así un relato marcado por la distancia: el protagonista y narrador vive desgajado y en conflicto con su entorno, en una continua 
lucha interna con él. En ambos textos, la rutina, la ausencia de aventura, de lo extraordinario, la monotonía de la vida cotidiana, la mediocridad y la violencia, producen el reconocimiento de que la ausencia de salida es la única experiencia posible para el hombre.

La vida que transcurre en un territorio donde nunca pasa nada significativo señala lo absurdo de cualquier esperanza o proyecto. $Y$ este es un punto de contacto con el relato de Padura : el encierro, el extrañamiento, el sentimiento de soledad, son en todos ellos una respuesta, una forma de defensa frente a un vacío o una ausencia de hechos trascendentes. Es irrelevante que se trate de relatos pertenecientes a países de estatuto político tan disímil : en cualquier caso no hay ningún futuro, nada para celebrar ni nadie con quien identificarse.

Sobreviene entonces un sentimiento de distancia e indiferencia con respecto al entorno, a la vida política y social y al resto de los ciudadanos; la búsqueda de la experiencia se vuelca hacia lo particular e individual. Agamben, en "¿Qué es lo contemporáneo?», sostiene que la contemporaneidad es « una relación singular con el propio tiempo, que adhiere a éste y, a la vez, toma su distancia » (19) ; es decir, se trata de un vínculo que implica una aceptación a la vez que « un desfase y un anacronismo ». Ese desacomodo es paradójicamente un signo que define a estos textos y a sus narradores como hijos de su tiempo -épocas poco acogedoras, sin duda- puesto que contemporáneo es aquel «que mantiene la mirada fija en su tiempo, para percibir, no sus luces, sino su oscuridad [...] es aquel que está en condiciones de escribir humedeciendo la pluma en la tiniebla del presente » (21).

Ese desfasaje produce el replieque hacia otras formas de experiencia y de este modo los textos apelan al contacto con los libros, las lecturas y la escritura. De hecho, La novela luminosa tiene su origen en el intento -frustrado, fracasado- de llevar al papel una experiencia personal « de gran trascendencia » cuya naturaleza jamás se explica ; leemos en la primera página :

Ciertas experiencias extraordinarias no pueden ser narradas sin que se desnaturalicen; es imposible llevarlas al papel (17). Todo este libro es testimonio de un gran fracaso [...] los hechos luminosos, al ser narrados, dejan de ser luminosos, decepcionan, suenan triviales. No son accesibles a la literatura, o por lo menos a mi literatura (23).

De este modo, la novela no podrá completarse, quedará trunca y jamás conoceremos esa experiencia que provocó la escritura. El prólogo -las quinientas páginas del diario de la beca- cubre ese hueco; el minucioso registro de lo rutinario y cotidiano la sustituye : el relato de lo nimio reemplaza a lo extraordinario.

El mundo de los libros es uno de los pocos espacios en el que los narradores se sienten cómodos; la escritura parece sin embargo un problemático refugio, en particular en Levrero, puesto que está invadida por la imposibilidad, por la pulsión contradictoria de escribir vs. no escribir. A su vez, en Lalo, la escritura es el muro, el retén que proteje de la hostilidad de lo real ${ }^{16}$; pero, en la medida en que el narrador pertenece a un mundo invisible, llevará la marca de la misma invisibilidad. Leer y escribir parecen ser las prácticas -por momentos agónicas- que permiten alguna forma de experiencia, las únicas con las que se alcanza alguna plenitud. En ellas se encuentran las huellas del fracaso político en Los países invisibles -y en El hombre que amaba los perros-o de la huida del mundo en La novela luminosa. Leer y escribir son la contracara del « excesivo deseo de no- 
participación » (60) que observa en sí mismo el narrador de Lalo mientras se encuentra en un evento social. ${ }^{17}$

La obsesiva referencia al acto de escribir permite dar cuenta de diversas formas del fracaso ; es índice de un conflicto, de una angustiosa lucha por existir, por sobrevivir a la invisibilidad, a la borradura política y literaria. ${ }^{18} \mathrm{La}$ escritura ha pasado a primer plano, el foco en ella permite protegerse del « afuera » que se distingue por sus múltiples formas de hostilidad ; permite también una distancia que obtura la emoción, ayuda al repliegue de los sentimientos y su represión -muy evidente en La novela luminosa. La narración se vuelca hacia la interioridad y su registro es minucioso, aunque desprovisto de sentimentalidad. A su vez, en Los países invisibles, la comprobación de la distancia entre su manera de ver el mundo y el entorno en el que vive, sume al sujeto en la tristeza : " por las vidrieras se ve el tráfico interminable de la carretera [...] Nos miramos por unos segundos y hay una tristeza indecible. Algo bajo, reptante, que nos come por dentro " (92) ; « invisibilidad y tristeza » (95) parecen entonces definir las emociones del narrador.

En los comienzos del siglo XXI y en este capitalismo tardío y global, el repliegue de la emoción hacia la interioridad y el relato de lo nimio parecen representar un nuevo estado de cosas : el fracaso de la experiencia social y de los proyectos políticos frente a la pérdida de las esperanzas utópicas. Los sujetos no se sienten implicados en ese mundo y retiran su afectividad, sufren un proceso de extrañamiento. El relato de la « historia mínima », de lo banal, su constante repetición, es la estrategia a la que recurre La novela luminosa : la escritura se ocupa entonces de reiterar y registrar lo "micro", refugio frente a una macrohistoria de la que no es posible más que sentirse desterrado. Repetir y refugiarse en lo nimio será entonces una manera de protegerse, no involucrarse, no sufrir, frente a una realidad que frustra y agrede; podemos pensar entonces en el ejercicio de una estética de lo nimio.

Ésta se manifiesta en la narración distanciada -en muchos casos desprovista de todo tipo de emoción- de los detalles y acciones aparentemente banales. En todos los casos, lo nimio reemplaza el relato de posibles hechos y episodios «importantes» que no se producen o se los vive como vacíos de sentido ; es en sí mismo una reflexión -en la doble acepción de pensar y reflejar- de situaciones y sentimientos ausentes o inexistentes. Lo nimio es lo que pasa cuando no pasa nada, es la forma de la experiencia cuando la emoción se sustrae al afuera, se retira el afecto del mundo social y el sujeto se repliega ante la carencia de trascendencia de ese exterior. Hay que recordar que lo nimio, según el diccionario de la Academia de la Lengua, es lo insignificante, pero también lo excesivo y lo minucioso. Los textos parecen explorar todas estas alternativas al mismo tiempo, basta con leer el obsesivo relato, ya mencionado, en La novela luminosa de la paulatina descomposición del cadáver de la paloma en una terraza frente a la casa del narrador : narración " objetiva », desprovista en absoluto de todo sentimiento, es, sin embargo, un espejo de la angustia y el sentimiento de muerte y sin sentido que atraviesa todo el "diario de la beca». Asimismo, en Los países invisibles, la descripción de espacios y cuestiones banales exponen a la vez sus sentimientos ocultos y la distancia que lo distingue de un ámbito vivido como extraño :

Estoy aquí ahora [...] pasando calor [...] escribiendo esto mientras escucho a mi lado a dos hombres conversar sobre transmisiones automáticas y modelos de automóviles [...] No estoy particularmente afectado por las circunstancias, porque es larga ya la vida pasada en esta pobreza pavimentada (130). 
El relato de su situación en los centros comerciales o en la carretera número 3 tiene una función semejante a la del cadáver de la paloma en Levrero : las palabras « destrucción » y « sin esperanzas » definen sus emociones y la carretera es un reflejo, una representación de lo que la vida no es : su experiencia entonces es de « cruda invisibilidad» (95). Lo banal funciona entonces como un signo de un mundo del cual el sujeto protagonista se siente expulsado, un mundo que le es extraño; vive una especie de exilio interior y establece con el exterior relaciones complejas, de rechazo y tensión. Se trata de un sujeto que articula simultáneamente el vínculo y el quiebre entre lo íntimo y lo externo, entre lo literario y lo político.

\section{El derrumbe del yo : política y desencanto}

Un exilio interior semejante vive el narrador de El hombre que amaba los perros, sin duda una novela en la que no es posible obviar lo político pero tampoco el proyecto estético que le da forma y lo organiza. Esta ligazón está en el origen del relato : se construye en torno al episodio del asesinato de Trotsky y al mismo tiempo evoca uno de sus textos más conocidos, La revolución traicionada. Acontecimiento y escritura conforman la novela que escribe -o reescribe- tanto un asesinato como una traición; es decir, está presente allí tanto lo factual como lo discursivo. Ambos, muerte y escritura, desencadenan entonces un discurso centrado en el destino de un hombre que encarna una revolución $y$, especialmente, una revolución traicionada.

La misma trayectoria de Padura como autor de relatos policiales lo liga a una tradición del género que se ha politizado en América Latina desde los relatos no ficcionales de Rodolfo Walsh y su fusión del testimonio con el código detectivesco. Este código sostiene en la mayoría de sus novelas la investigación, el consiguiente desencanto por la imposibilidad de justicia y la derrota del héroe ; sin embargo, en El hombre que amaba los perros, aunque se trata también de la búsqueda de una verdad oculta para la que toda justicia se vuelve improbable, donde el fracaso del protagonista es radical, el relato se aleja del género y lleva a otros vínculos literarios. Podría decirse que la estructura del policial abandona el plano argumental y pasa a sostener el relato mismo construido en la forma de sucesivas indagaciones en torno a lo silenciado; es decir se vuelve un problema de la escritura, ya no de la historia contada. Y es aquí donde el contacto entre política y estética pasa a primer plano: en El hombre que amaba a los perros se entrecruzan tres historias y tres investigaciones : dos de ellas íntimamente vinculadas a la Historia (con mayúscula), que se enfocan en Trotsky y en Ramón Mercader, su asesino. En ambas, y en especial en la primera, el lector puede encontrar los rastros de una pesquisa exhaustiva y una fuerte presencia del discurso histórico como referencia dominante. La tercera, tiene un protagonista y narrador que nuevamente nos remite al juego autoficcional mencionado al comienzo de este trabajo, pero también -por el ambiguo efecto del vínculo entre ficción y referencia- a la novela La segunda muerte de Ramón Mercader de Jorge Semprún. ${ }^{19}$ Claro está que la diversidad de estéticas -el nouveau roman en este caso y un relato con fuerte impronta histórica en el otro- parecen producir un efecto distinto : muchos lectores estarían dispuestos a considerar la novela de Padura un claro relato político y La segunda muerte... una historia de espías con suspenso donde lo político (la guerra civil española, la muerte de Trotsky y los oscuros manejos del PC) es un elemento más que contribuye a la complejidad y ambigüedad de la trama. 
32 Sin embargo, las estrategias narrativas tienen puntos de contacto: en particular, el narrador-protagonista de Padura produce el mismo efecto de « confusión » o mezcla con lo referencial que se genera en la novela de Semprún. En ésta, el sujeto de enunciación comenta sobre las alternativas novelescas y el hacer de la escritura en un gesto muy autorreflexivo y acentúa el juego de ambigüedades al entrecruzar a la familia Semprún con la trama ficcional : abundan las alusiones a episodios de la vida del autor y de su padre, miembro del gobierno republicano español, supuestamente relacionado con el padre del protagonista; de hecho, éste último podría ser pensado como un alter ego del autor por su condición de miembro del PC y la doble identidad con que vive en España. Estos rasgos se han leído como un juego «ficción/realidad» característico del nouveau roman-movimiento del que Semprún formó parte-, de su modo de incluir y diluir lo referencial en el juego antirrealista y antirrepresentativo. La novela de Padura parece estéticamente muy lejana a la de Semprún; sin embargo, una mirada atenta comienza a encontrar puntos en común que no se limitan a lo temático. También aquí los datos que el lector posee del autor apuestan al juego del « simulacro autobiográfico » : en El hombre que amaba a los perros el narrador nos señala su interés por el relato policial y su fascinación por Chandler, del que sale el título del libro. ${ }^{20}$ Se trata de otra huella de su vínculo con el género -similar al del autor- en este caso con un clásico que ha sido fundamental en su desarrollo en Latinoamérica; pero sobre todo la alusión a su « amigo y congénere Mario Conde » (488), detective protagonista de la mayoría de las novelas policiales de Padura, es un claro gesto de complicidad con el lector. Ese narrador, Iván, se delinea como un doble de Conde (como él está en busca de una verdad y lo espera la derrota), pero también es un doble del « autor Padura » quien cierra todas las historias, las búsquedas y los fracasos en la nota final donde de algún modo se equipara a Iván.

Es imposible obviar que se está leyendo un texto construido a base de la superposición de relatos : la novela insiste en esta condición narrativa a la vez que se vuelve -justamente a través de la reafirmación constante de esa escritura- hacia la referencia histórica. ${ }^{21} \mathrm{El}$ narrador Iván, su amigo Daniel que recoge el manuscrito y finalmente el autor Padura establecen un constante equilibrio inestable entre la referencia simultánea a lo históricopolítico y a la escritura. Otra vez un sujeto narrador, que parece duplicarse en el autor, articula el « adentro » y el « afuera » de la historia : la sección dedicada al narrador Iván condensa los diferentes tiempos y momentos políticos revolucionarios (los de Trotsky, los de Mercader y los del personaje cubano) en que el PC stalinista ha torcido un mismo proyecto en Rusia, durante la guerra civil española y en Cuba. Iván encarna el derrumbre de las ilusiones que sostuvieron los tres procesos (y de hecho muere al desplomarse el techo de su casa); su encuentro con Mercader es el episodio "pivote» que permite la fusión de las historias. Ahí es cuando Iván descubre su miedo, unido siempre al temor de escribir la historia, miedo que alcanza al autor Padura en la nota final cuando explicita su identificación con el personaje : "Cinco años de dudas y miedos (¿recuerdan a Iván ?)» (573). En este cierre el autor Padura sufre, frente a la escritura de su novela, la misma incertidumbre que Iván, casi su doble, su « simulacro autobiográfico ». Miedo, escritura, desencanto y naufragio han definido la vida de Iván que es una sinécdoque, una metáfora de su generación (la misma que la del autor Padura) en Cuba.

La novela constituye entonces una lectura del fracaso de un proyecto histórico en manos de una burocracia heredera de la stalinista. Las coincidencias entre Iván y Padura evidencian el procedimiento de "ficción de autor » en el texto al mismo tiempo que producen un efecto de veracidad en lo político e histórico. La biografía de los personajes 
reales, entrecruzada con la ficcional que -a su vez- parece evocar rasgos atribuibles al autor, produce «un efecto de verdad». Sin duda, la muerte de Trotsky es el acontecimiento literario, político e histórico a partir del cual el texto piensa el presente de la escritura. El asesinato como una traición al proyecto revolucionario desencadena un relato que lo lee como el epítome de una trayectoria cuyas consecuencias todavía se están desarrollando ; es decir, las profecías de Trotsky « acaban cumpliéndose » y la revolución es traicionada, tal como lo anunciaba su ensayo de 1937.

Encontramos entonces, a pesar de la diferencia entre las estéticas a las que pertenecen los relatos tratados, un sujeto que resulta nexo entre ficción y referencia, entre lo político y lo estético. Peter Bürger, en su excelente ensayo La desaparición del sujeto, afirma que la reconsideración actual del sujeto puede leerse como signo de « un deslizamiento epocal » (16) dentro de la categoría misma. Es decir, estamos ante lo que llama « un campo de subjetividad (329) que abre un espacio de posibles y nuevas determinaciones para esta figura. Sin duda, estas novelas comparten estrategias « epocales », entre las que el yo, esa enunciación que parece desplazarse continuamente, mantiene en tensión el proceso de escritura y, a la vez, se escinde : entre el yo que escribe y el yo descrito, entre el acto de escribir y ese mundo de " afuera » que se impone y al que se rechaza simultáneamente.

En resumen, los textos tienen en común ciertos procedimientos narrativos, pero también un " aire de derrota ", ya sea una derrota puntual o no, relacionada a episodios históricos precisos $\mathrm{u}$ omitidos (como podría ser la casi total falta de mención a la dictadura y posdictadura uruguaya en el caso de Levrero) ; estos relatos plantean una derrota radical a la que se ha llegado sin remedio y en un territorio que resulta invivible y por el que se transita en perpetuo exilio. Si en ellos existe algo parecido a una resistencia, ella no está destinada a la espera de un futuro mejor y de algún modo utópico, sino que es una pura resistencia a pertenecer, es un acto de exclusión y rechazo del presente tal como es.

Los protagonistas buscan el aislamiento, optan por la indiferencia o la apatía y demuestran la vacuidad de cualquier esperanza en el futuro; « vivir [...] sin las trampas de la esperanza, es decir, des-esperado " (143, la bastardilla es del autor) se dice en Los países invisibles y la consigna vale para las otras novelas. En cualquier caso queda demostrada la inutilidad de toda participación o entusiasmo por un mundo muy distante de las ilusiones y los proyectos del siglo XX. En la novela de Levrero, la imposibilidad de escribir del protagonista, su dispersión en tareas nimias, su intolerancia a la vida en la ciudad, son índices de la distancia entre el presente y las promesas de un "luminoso" futuro hechas en el pasado; en el caso de Lalo, la pertenencia a un país colonial que ninguna gesta tiene para celebrar o añorar, construye un personaje/narrador y un mundo doblemente «invisibles"; en la nota final de El hombre que amaba los perros, Padura se propone reflexionar sobre « la perversión de la gran utopía del siglo XX, ese proceso en el que muchos invirtieron sus esperanzas, tantos hemos perdido sueños, años y hasta sangre y vida » (571). Las novelas se cierran entonces con el mismo desencanto, por eso es bueno recordar aquí a Rancière cuando sostiene que la voluntad de repolitizar el arte se manifiesta en prácticas muy distintas ; es decir, a pesar de la diversidad de sus estéticas, comparten estrategias y se parecen notablemente en sus evaluaciones políticas puesto que la relación con la referencialidad, lo explícito o no del relato, no definen su politicidad.

La función de la literatura para esta narrativa parece ser dejar constancia, replegándose en el espacio de la interioridad, de las máscaras complacientes que encubren los fracasos de las últimas décadas. El repliegue de los narradores, el rechazo de todo centro cultural, 
social o político hacia alguna forma de margen nos lleva a relacionar los textos con debates muy actuales en torno a lo político. Se pueden leer los dos primeros como representaciones de la degradación que sufrió la práctica política durante los años noventa en gran parte de América Latina ; degradación que generó la pérdida y el olvido de su sentido mismo como campo de reflexión y praxis simultáneos; y en el caso de $E l$ hombre que amaba los perros, como resultado del desencanto que sobrevino a la caída de las utopías en los ochenta y noventa. Estos narradores no se plantean ya una confrontación o una búsqueda de nuevas formas de actividad política ; por el contrario, el retroceso frente a la acción, el fracaso de toda experiencia, provoca un repliegue definitivo. Es posible que estos sujetos constituyan un paso más en las representaciones de derrota: lejos ya de otras figuras de perdedores en los que todavía podía leerse ese rechazo a toda participación como una forma de resistencia con vistas al futuro, es posible que afirmen por medio de ese juego autoficcional, de ese « simulacro » que oscila entre la ficción y lo real, lo irreductible del desastre en nuestro mundo del presente.

\section{BIBLIOGRAFÍA}

Agamben, Giorgio. "¿Qué es lo contemporáneo?». Desnudez. Buenos Aires : Adriana Hidalgo, 2011.

Agamben, Giorgio. Infancia e historia. Destrucción de la experiencia y origen de la historia. Buenos Aires : Adriana Hidalgo, 2001.

Alberca, Manuel. El pacto ambiguo. De la novela autobiográfica a la autoficción. Madrid : Biblioteca Nueva, 2007.

Amar Sánchez, Ana María. Instrucciones para la derrota. Narrativas éticas y políticas de perdedores. Barcelona : Anthropos, 2010.

Amícola, José. Estéticas bastardas. Buenos Aires : Biblos, 2012.

Bürger, Peter y Christa Bürger. La desaparición del sujeto. Una historia de la subjetividad de Montaigne a Blanchot. Madrid : Akal, 2001.

Cabrera Infante, Guillermo. Tres tristes tigres. Barcelona : Seix Barral, 1968.

Chandler, Raymond. « El hombre que amaba a los perros ». Asesino en la lluvia. Barcelona : Bruguera, 1978.

Derrida, Jacques. « Políticas del nombre propio ». Sujeto y relato. Ed. María Stoopen Galán. México : UNAM, 2009, pp. 289-312.

Foucault, Michel. « ¿Qué es un autor?». Conjetural 4, agosto 1984 (87-111).

Lalo, Eduardo. Simone. Buenos Aires : Corregidor, 2011.

Lalo, Eduardo. Países invisibles. San Juan : Tal Cual, 2008.

Lalo, Eduardo. donde. San Juan : Tal Cual, 2005.

Levrero, Mario. Irrupciones. Montevideo : Santillana, 2007. 
Levrero, Mario. La novela luminosa. Montevideo : Alfaguara, 2005.

Levrero, Mario. El discurso vacío. Montevideo : Trilce, 1996.

Molero de la Iglesia, Alicia. La autoficción en España : Jorge Semprún, Carlos Barral, Luis Goytisolo, Enriqueta Antolín y Antonio Muñoz Molina. Bern : Peter Lang, 2000.

Morales-Rivera, Santiago. « La imaginación desmadrada de Juan José Millás : humor y melancolía en La soledad era esto ». Revista Hispánica Moderna 64.2, 2011 (129-148).

Padura, Leonardo. El hombre que amaba los perros. México : Tusquets, 2009.

Premat, Julio. Héroes sin atributos. Buenos Aires : FCE, 2009.

Rancière, Jacques. « Las paradojas del arte político ». El espectador emancipado. Buenos Aires :

Manantial, 2010, pp. 53-84.

Rancière, Jacques. Sobre políticas estéticas. Barcelona : Universitat Autonoma, 2005.

Semprún, Jorge. La segunda muerte de Ramón Mercader. Caracas : Tiempo Nuevo, 1970.

Trotsky, León. La revolución traicionada. Buenos Aires : Claridad, 1938.

\section{NOTAS}

1. Rancière señala: "no hay ningún conflicto entre la pureza del arte y su politización. Al contrario, en función de su pureza la materialidad del arte se propone como materialidad anticipada de una configuración distinta de la comunidad» (2005: 27). En un estudio posterior, «Las paradojas del arte político », sostiene que « un arte crítico es un arte que sabe que su efecto político pasa por la distancia estética » $(2010: 84)$, es decir, « lo que se llama política del arte es el entrelazamiento de lógicas heterogéneas » $(2010: 66)$.

2. Si bien Serge Doubrovsky utilizó el término por primera vez en 1977 para definir su relato Fils como una "ficción de acontecimientos reales", es sobre todo Manuel Alberca quien se ha ocupado de formular una teoría sistemática del concepto.

3. Agamben, en " El autor como gesto », analiza el concepto de «función-autor » y recuerda que Foucault opone drásticamente el autor-individuo real y la función-autor, la única sobre la que concentra su análisis ; " existe un sujeto-autor, y sin embargo él se afirma sólo a través de las huellas de su ausencia » (85).

4. Molero de la Iglesia destaca esta vacilación cuando señala la dificultad de determinar si las obras autoficcionales, publicadas como narrativa, responden a un nuevo modelo de relato autobiográfico, o por el contrario, son un nuevo tipo de discurso novelesco, con contenido autobiográfico. Se trata de un procedimiento retórico destinado a borrar la distancia entre discurso histórico y ficticio que se aleja de lo autobiográfico, aunque responde -según la autora- a la necesidad de mostrar la conciencia dividida y múltiple que caracteriza al sujeto del presente.

5. Alberca entiende su trabajo como un aporte a la comprensión del proceso de « recuperación del autor en la literatura española de las últimas décadas » (31). Por otra parte, entiende que la práctica de la autoficción se sostiene en la confusión entre persona y personaje, « insinuando, de manera confusa y contradictoria, que ese personaje es y no es el autor » $(32$, la bastardilla es del autor).

6. Premat explicita que el objeto teórico estudiado en su libro es « la invención de una figura de autor » en la literatura argentina y deja claro que « ver en él una ficción implica leerlo a partir de la ambivalencia de cualquier ficción : polisémico, a medias entre lo biográfico y lo imaginado, a la 
vez fantasmático y socialmente determinado [...] y en todo caso, operativo en la circulación de sus textos » (28).

7. No es posible dar cuenta en los límites de este trabajo de toda la discusión y diversidad de posiciones sobre la autoficción; desarrollo de forma más extensa este debate teórico en mi próximo libro del que este artículo forma parte.

8. Aunque La novela luminosa es central para la argumentación de este trabajo, es importante recordar que continúa de alguna manera sus textos previos "Diario de un canalla" (1922) y El discurso vacío (1996) y está vinculada con su colección de notas periodísticas Irrupciones, editadas en 2007 ; lo mismo vale para el nexo que une Países invisibles con un texto anterior, donde (2005), y con Simone, publicado tres años después. Me referí más extensamente a estos relatos y a la relación entre la producción de ambos autores en el trabajo « Afectos esquivos : una estética para una política » de próxima publicación en la antología Políticas de la emoción en producciones culturales de América Latina de Editorial Iberoamericana.

9. Quisiera subrayar que no intento aquí asimilar un relato al otro, sólo me interesa analizar ciertas estrategias comunes, quizá un " gesto epocal », apelando al término usado por Bürger, en autores aparentemente en nada vinculados entre sí.

10. En la « Nota muy agradecida » que cierra la novela de Padura leemos : « me atuve con toda la fidelidad posible (recuérdese que se trata de una novela [...]) a los episodios y la cronología de la vida de Leon Trotski [...] Este ejercicio entre realidad verificable y ficción es válido para el caso de Mercader como para el de otros muchos personajes reales que aparecen en el relato novelesco repito : novelesco- y por lo tanto organizado de acuerdo con las libertades y exigencias de la ficción » (571).

11. Ya en el final del texto de Levrero, «Epílogo del diario », leemos : « Me hubiera gustado que el diario de la beca pudiera leerse como una novela ; tenía la vaga esperanza de que todas las líneas argumentales abiertas tuvieran alguna forma de remate. Desde luego, no fue así, y este libro, en su conjunto, es una muestra o un museo de historias inconclusas » (537).

12. También pueden encontrarse en El hombre que amaba a los perros numerosos procedimientos característicos de una narrativa autorreferencial más que histórica o biográfica : identidades que se duplican y confunden, personajes que son condensaciones o sinécdoques de momentos históricos y repeticiones que producen el efecto de espejo entre las tres secciones.

13. En Lalo, la oposición visible vs. invisible es política : implica en términos generales Primer Mundo vs. Tercer Mundo, aunque incluye todo espacio olvidado, « invisibilizado » por los centros de poder político y cultural : «Puerto Rico es invisible en España. Nuestro gentilicio es la imagen máxima del mínimo espesor, de lo que no despierta interés ni atención. La invisibilidad del mundo le permite a ciertos pueblos la simplificación del mundo» (67).

14. El narrador-autor de Levrero afirma al hablar de la literatura : "muchas veces yo he dicho y escrito : "Si yo quisiera transmitir un mensaje ideológico, escribiría un panfleto" [...] Pero eso no quiere decir que en mi literatura no se expongan ideas, y que no valga la pena mencionar esas ideas » (124, la bastardilla es del autor).

15. Esta es una de las pocas referencias directas en el texto a la dictadura militar terminada años antes.

16. En La novela luminosa esa función está a cargo de la adicción a la computadora y de los sueños, modos de escape o espacios donde se descifra la incomprensible del mundo : «Y estas adicciones que me perturban actualmente son [...] un medio de abreviar el tiempo, de que el tiempo pase sin que yo sienta dolor » (137).

17. El mismo « deseo de no-participación » y extrañamiento caracteriza al protagonista del diario de La novela luminosa: "llego a un lugar y ya me estoy despidiendo [...] ya me estoy yendo, imcompleto [...] con esa manera de sentir soy extranjero en todas partes. A veces hasta en mi casa » (243). Y también el narrador de El hombre... se ha hundido en la apatía, él ha « traspasado la frontera de la nada y alcanzado casi la invisibilidad » (492). 
18. Los textos despliegan una verdadera pasión por referirse al acto de escribir, a su dificultad, a la impotencia ante la página en blanco (La novela luminosa), a su inutilidad (Países invisibles), al miedo que acarrea (El hombre que amaba los perros).

19. Puede leerse la novela de Padura como reescritura y cita de una historia ya contada en La segunda muerte de Ramón Mercader (1970) y también en la sección «La muerte de Trotsky referida por varios escritores cubanos, años después -o antes » perteneciente a Tres tristes tigres (1965) de Guillermo Cabrera Infante. El análisis de los vínculos entre estos tres relatos lo desarrollo en el libro en preparación del que este trabajo forma parte.

20. Hay que recordar que «El hombre que amaba a los perros » es un cuento perteneciente a la colección Asesino en la lluvia del autor norteamericano.

21. «Percibí, como una necesidad visceral de aquella historia, la existencia de otra voz, otra perspectiva, capaz de complementar y contrastar lo que me había contado el hombre que amaba a los perros » (408); «Voy a terminar de escribir cómo lo conocí y por qué no me atreví desde el principio a contar su historia » (562) ; « ¿Sabes para qué te contó su historia y después hizo esta carta ? [...] Pues para que tú lo escribieras y lo publicaras » (563).

\section{RESÚMENES}

El trabajo se enfoca en la producción de tres autores, el uruguayo Mario Levrero (La novela luminosa, 2005), el puertorriqueño Eduardo Lalo (Países invisibles, 2008) y el cubano Leonardo Padura (El hombre que amaba los perros, 2009). Estos textos no sólo comparten la cercanía temporal sino que coinciden en parecer "inclasificables" por su imprecisa condición genérica y por un uso de la voz narrativa igualmente complejo y ambiguo. Se analizan las estrategias de "autoficción", es decir las formas que adquieren las representaciones del yo (que también han sido llamadas "ficciones de autor" o "simulacros autobiográficos") y de las emociones en tres relatos bien distintos. Los dos primeros, centrados en el registro minucioso de lo trivial e insignificante del mundo cotidiano, no se plantean abiertamente como una narrativa política, por el contrario, en ellos parecen primar las preocupaciones estéticas. A su vez, la novela de Padura se presenta como un claro texto político, incluso biográfico-histórico. Sin embargo, todos parecen dejar constancia de la desilusión y desencanto que ha producido la pérdida de las utopías sociales y políticas del siglo XX.

Le travail est axé sur l'oeuvre de trois auteurs, l'Uruguayen Mario Levrero (La novela luminosa, 2005), le Portoricain Eduardo Lalo (Países invisibles, 2008) et le Cubain Leonardo Padura (El hombre que amaba los perros, 2009). Ces textes ont en commun leur parution à des dates rapprochées ainsi que leur nature en apparence " inclassable ", dûe à une peu précise inscription dans le genre et à un emploi de la voix narrative également complexe et ambigu. L'auteur analyse les stratégies "autofictionnelles», c'est-à-dire les formes que revêtent les représentations du moi (qu'on a aussi appelées «fictions d'auteur» ou "simulacres autobiographiques») et des émotions dans ces trois récits par ailleurs fort différents. Les deux premiers, axés sur un registre minutieux de la trivialité et l'insignifiance des choses de la vie quotidienne, ne se présentent pas ouvertement comme des narrations politiques, ce sont au contraire les problèmes esthétiques qui paraissent y avoir la priorité. Le roman de Padura se présente en revanche comme un texte clairement politique, et même biographique et historique. Malgré cela, tous ces textes semblent dresser un 
constat de la désillusion et le désenchantement produits par la perte des utopies sociales et politiques du XX siècle.

The study focuses on the production of three authors, the Uruguayan Mario Levrero (La novela luminosa, 2005), the Puerto Rican Eduardo Lalo (Países invisibles, 2008), and the Cuban Leonardo Padura (El hombre que amaba los perros, 2009). Aside from their temporal closeness, the works also share an apparent "unclassifiability" that results from their imprecise generic condition and use of a complex and ambiguous narrative voice. The study analyzes strategies of "autofiction," or representations of the "I" (also called "fictions of the author" or "autobiographical simulacra") and emotions in three very different works. The first two texts, centered on trivial and insignificant quotidian details, do not initially appear to be political narrative, but rather seem to privilege aesthetic concerns. Padura's novel is clearly a political text, if not also biographicalhistorical. All three, however, record the disillusion and disenchantment to result from the disappearance of the twentieth century's social and political utopias.

\section{ÍNDICE}

Mots-clés: Autofiction, esthétique, politique, désenchantement, distopie

Palabras claves: Autoficción, estética, política, desencanto, distopía

Keywords: aesthetics, politics, disenchantment, dystopia

\section{AUTOR}

\section{ANA MARÍA AMAR SÁNCHEZ}

University of California-Irvine aamarsan@uci.edu 